\title{
CONNECTING SOCIAL MEDIA AND TRADITIONAL MEDIA: BEST \& WORST PRACTICES
}

\author{
Andy Rohm, Loyola Marymount University, USA \\ Richard Hanna, Northeastern University, USA \\ Victoria Crittenden, Boston College, USA
}

\begin{abstract}
Companies today seeking to establish closer customer relationships face a daunting task: how to develop and manage their social media marketing platforms and align them with traditional media. However, there is little agreement on what performance metrics should be used to evaluate social media campaigns. Furthermore, questions remain regarding the role social media plays in the firm's overall marketing campaign. While consumers are adopting increasingly active roles in cocreating marketing content along with companies and their respective brands, many firms still are less comfortable relinquishing control of their brand message within the unstructured social media environment. The challenge facing companies is that, although they recognize the need to be active in social media, they don't truly understand how to do it effectively, what performance indicators they should be measuring, and how they should be measured. In this paper, we examine different approaches by firms to use social media in conjunction with their traditional media. We apply different performance metrics to these campaigns and measure consumer reaction. We highlight best practices across several firms' efforts to leverage social media in order to reach the important youth audience, and we conclude with insights and lessons related to the strategic integration of social media into firms' existing marketing communications strategies.
\end{abstract}

